composing an intervention programme will be planned in joint effort by a constructive dialogue between employee and supervisor. The aim of this qualitative study was assess the needs of employees and supervisors towards the aforementioned approach to improve sustainable employability of nurses.

Method A structured needs assessment was performed to answer the question of what are the realistic, attainable and useful characteristics of an intervention, in which nurses and their supervisors have a constructive dialogue on sustainable employability. The so-called Vitality Scan is filled out beforehand and used as a starting point of the dialogue, during which customised follow-up actions are arranged if appropriate. We performed six focusgroup interviews, three amongst employees $(n=13)$ and three amongst supervisors $(n=15)$. Qualitative data analysis was performed using Atlas.ti.

Results Both employees and supervisors perceived a safe psychosocial working environment as most essential. We found a positive attitude and intention towards the characteristics of the Vitality Scan and dialogue. The (time) effort and amount of self-efficacy amongst supervisors were considered potential barriers as well as facilitators. Thorough training of the supervisors was considered necessary.

Conclusion Nurses and supervisors are positive towards working on sustainable employability of nursing staff using the designed intervention. Several existing facilitators and barriers in the organisation were addressed and practical improvements were suggested.

\section{PSYCHOSOCIAL RISKS IN TRADE UNION REPRESENTATIVES}

${ }^{1} S$ Ronsmans*, 2,3 L Godderis. ' $\mathrm{KU}$ Leuven - University of Leuven, student Master of Occupational Medicine, Leuven, Belgium; ${ }^{2}$ KU Leuven - University of Leuven, Department of Public Health and Primary Care, Environment and Health, Leuven, Belgium; ${ }^{3} I D E W E$, External Service for Prevention and Protection at Work, Heverlee, Belgium

\subsection{6/oemed-2018-ICOHabstracts.1725}

Introduction Quantitative studies reveal that trade union representatives are dealing with a number of specific psychosocial risk factors. The existing literature leaves many questions unanswered on the underlying reasons for these psychosocial risks and on difficulties in addressing them. A qualitative research could offer an opportunity to tackle this knowledge gap and to provide deeper understanding of this subject.

Methods Eight semi-structured in-depth interviews were conducted with trade union representatives from the 2 largest Belgian unions: ACV (Confederation of Christian Trade Unions) and ABVV (General Federation of Belgian Labour). A purposeful sample of participants was recruited from a wide range of sectors and types of work organisation. Template analysis was used to examine their unique job demands and job resources.

Results Using the job demands-resources model as a conceptual framework it was possible to map the unique psychosocial risk factors experienced by trade union representatives. Quantitative, qualitative and emotional overload, role conflict, role ambiguity and a conflictual relationship with their employers were found to be the major job demands. Social support from the workers, other representatives and the trade union were found to be the most important job resources, as well as having the knowledge and skills, experiencing success and having strong trade union beliefs. The findings of this study also suggest that workplace restructuring could profoundly impact the job demands and job resources experienced by trade union representatives.

Conclusions A rich and complex account of the experiences of the participants could be created. In general the results fit the existing literature but they add a deeper understanding of how and why trade union representatives are experiencing certain job demands and job resources. The study resulted in a wide range of propositions to improve the prevention of psychosocial risks in trade union representatives.

\section{EFFICIENCY OF VOCATIONAL REHABILITATION PROGRAMS FOR WORKERS WITH SCHIZOPHRENIA: A SYSTEMATIC LITERATURE REVIEW ACCORDING TO THE PRISMA GUIDELINES}

${ }^{1} \mathrm{~A}-\mathrm{E}$ Leverich, ${ }^{1} \mathrm{~S}$ Acke*, $1,2 \mathrm{M}$ Verbrugghe, ${ }^{1} \mathrm{M}-\mathrm{N}$ Schmickler, ${ }^{3} \mathrm{C}$ De Brouwer. ${ }^{1} \mathrm{Mensura}$ Occupational Health Services, Belgium; ${ }^{2}$ Department of Public Health, University of Ghent, Belgium; ${ }^{3}$ Environmental health and Occupational health, Université libre de Bruxelles, Belgium

\subsection{6/oemed-2018-ICOHabstracts. 1726}

Introduction Unemployment is common among people with schizophrenia and contributes most to the economic cost of the condition. This study was aimed at (1) reviewing the available tools to facilitate the vocational rehabilitation of workers with schizophrenia and (2) describing their specific opportunities.

Methods A search of PubMed for original, peer-reviewed articles published from 2006 until January 31, 2016, yielded 643 citations. Exclusion criteria were patients less than 18 years or older than 65 years of age, patients with additional diagnoses, studies conducted in developing countries, lack of an adequate study design, systematic reviews or case studies, no work related studies, and other major analytic inadequacies. The remaining 24 articles were assessed in qualitative synthesis using the Scottish Intercollegiate Guidelines Network (score $\geq 2+$ ), Critical Appraisal Skills Program or Prediction Model Risk of Bias Assessment Tool checklists.

Results

- Only seven quantitative and one qualitative study could be included. The number of study participants with schizophrenia varied substantially $(n=7$ in the qualitative study, $\mathrm{n}=100$ in the largest quantitative study). Most studies were conducted in the United States $(n=5)$, as well as two in Canada and one in Japan.

- Cognitive remediation programs (Neurocognitive Enhancement Therapy) combined with supported employment were significantly more effective $(\mathrm{p}<0.005)$ than supported employment by itself. Next, Individual Placement and Support (the manual version of supported employment) and cognitive behavioural therapy (Indianapolis Vocational Intervention Program) were, by themselves, more effective than conventional vocational rehabilitation, regardless of whether it was for competitive employment.

Discussion Combining cognitive remediation programs with supported employment programs significantly improved the vocational outcomes of workers with schizophrenia, especially 
for those with lower community functioning. Participation in competitive employment was also promoted by shorter initial working hours, higher education and disclosure of disabilities. Future prospective, longitudinal research with larger samples, in stratified baseline conditions, is needed.

\section{EVALUATION OF SUBJECTIVE SCALES FOR MEASURING MENTAL WORKLOAD: LITERATURE REVIEW}

${ }^{1}$ FF Alpert*, 'DS Harada, ${ }^{2}$ FR Bonnet, ${ }^{3} \mathrm{KJP}$ Campos, ${ }^{3} \mathrm{MJF}$ Gimenes, ${ }^{4}$ EC Sá, ${ }^{5}$ DR Muñoz. ${ }^{1}$ Occupational and Environmental Medicine (OEM) Residents, University of São Paulo (USP), São Paulo, Brazil; ${ }^{2}$ Preceptor, OEM Residency Program, USP, São Paulo, Brazil; ${ }^{3}$ Associate Professor, OEM Residency Program, USP, São Paulo, Brazil; ${ }^{4}$ Supervisor, OEM Residency Program, USP, São Paulo, Brazil; ${ }^{5}$ Head Professor, OEM Residency Program, USP, São Paulo, Brazil

\subsection{6/oemed-2018-ICOHabstracts.1727}

Introduction Workers' mental health should be valued since the causes of work abandonment due to problems related to mental health already occupy the first position in the statistics in some countries. Knowledge about the means of measuring the mental load in the work environment can help the occupational health team to identify causes of absence, propose ways of prevention, seeking a better adaptation of the work cycle to the worker. The comprehension of the measurement methods available in the literature also helps to guide the choice of the most appropriate scale according to the type of demand to be applied.

Methods Literature review about the forms of evaluation of mental workload, carried out between June and November of 2016, using the following descriptors combined: 'occupational mental load', 'Mental work load', and 'NASA-TLX' at SciELO, Lilacs and Medline databases.

Result A total of 34 articles were selected, of which $80 \%$ used the NASA-TLX scale as a method of analysis or as a comparison for validation of new scales.

Discussion The mental workload scales should be selected according to what is prioritised in the research results. In addition, variability may occur in the application of the same scale with different populations; which corroborates with the definition that the mental load has factors that are specific to the individual and his sociocultural environment. Thus, external and personal factors may interfere in different ways in the assessment of mental load expenditures according to the task.

\section{MENTAL DISORDERS AMONG URBAN BUS DRIVERS}

${ }^{1}$ FF Alpert ${ }^{*},{ }^{1} D S$ Harada, ${ }^{2}$ FR Bonnet, ${ }^{3} \mathrm{MV}$ Braga, ${ }^{3} \mathrm{CM}$ Medeiros, ${ }^{4}$ EC Sá, ${ }^{5} \mathrm{DR}$ Muñoz. ${ }^{1}$ Occupational and Environmental Medicine (OEM) Residents, University of São Paulo (USP), São Paulo, Brazil; ${ }^{2}$ Preceptor, OEM Residency Program, USP, São Paulo, Brazil; ${ }^{3}$ Associate Professor, OEM Residency Program, USP, São Paulo, Brazil; ${ }^{4}$ Supervisor, OEM Residency Program, USP, São Paulo, Brazil; ${ }^{5}$ Head Professor, OEM Residency Program, USP, São Paulo, Brazil

\subsection{6/oemed-2018-ICOHabstracts. 1728}

Introduction The urban bus driver work has several implications, being of great importance the fact that it develops in a public environment. The traffic isn't a defined workspace, being an environment of constant shift and, for that reason, differently from most workers, the bus driver practice his labour outside of the territorially demarcated business environment. This situation exposes this profession to the interference of a diversity of risk factors that many times are out of the scope of its competence. The aim of this study was to identify the most prevalent risk factors and prevention strategies to avoid the illness among the urban bus drivers, in the period of 2006-2016.

Methods A literature survey involving the subject of mental health and the urban bus drivers was made by a direct consultation of scientific articles published in Scielo, Lilacs and Medline database, published from 2006 to 2016.

Result After peer-reading and selection of abstracts according to the parameters described above, fourteen articles were selected and analysed.

Discussion The labour influences the physiological and mental state of the driver, which can lead to irritability, insomnia and attention disturbances. The act of driving is exhausting and its performance is related specially to environment factors of the labour working space and the individual form of coping. Therefore, labour and health conditions of the urban collective bus driver may be considered as psychic and organic pathologies sources. The organisational aspect of labour exerts a great influence over the psychic disorders in this group of professionals, such as the relationship with bosses and colleagues, stability and professional bond and work requirement in relation to the conditions offered. External factors such as road conditions, intense traffic, transit regulations and violence, also exerts a strong influence over the psychosocial health of the urban bus driver.

\section{IS THERE A RELATIONSHIP BETWEEN LEADERSHIP AND PRESENTEEISM?}

${ }^{1} \mathrm{~N}$ Amler*, ${ }^{2} \mathrm{M}$ Hasenbrinck, 'W Fischmann, ${ }^{1} \mathrm{~A}$ Voss, ${ }^{1} \mathrm{E}$ Wischlitzki, ${ }^{2} \mathrm{O}$ Schöffski, ${ }^{1} \mathrm{H}$ Drexler. ${ }^{1}$ Institute of Occupational, Social and Environmental Medicine, University Erlangen-Nuremberg, Erlangen, Germany; ${ }^{2}$ Chair of Health Management, University Erlangen-Nuremberg, Nuremberg, Germany

\subsection{6/oemed-2018-ICOHabstracts. 1729}

Introduction According to the literature presenteeism (defined as people turning up at work despite illness) is closely related to work related factors such as high job demands, time pressure or difficulties in staff replacement. On the other hand, there is growing evidence that managers and supervisors have a huge impact on employees' health and well-being. We have been wondering if leadership also has an effect on employees' behaviour in case of illness.

Methods PubMed, Business Source Complete and PsycINFO were searched for relevant literature. Internet search and scanning reference lists complemented our search. Two authors independently reviewed titles, assessed articles' eligibility and extracted relevant data. Papers examining presenteeism in the context of management or leadership were included. Articles in languages other than English or German were excluded from further research.

Results In total 418 studies were identified. 27 met the inclusion criteria. The majority of studies addressed the role of managers with regard to the disclosure of diseases, within return-to-work discussions or in integration management. Others analysed the impact of different leadership styles on presenteeism in general. Studies suggest that the leaders' own behaviours in case of illness as well as their attitudes towards 